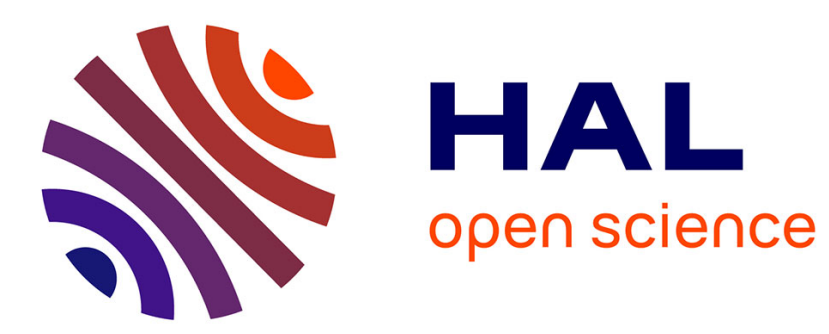

\title{
On the entanglement of electrostriction and non-linear piezoelectricity in non-centrosymmetric materials
}

\author{
Laurent Pedesseau, Claudine Katan, Jacky Even
}

\section{To cite this version:}

Laurent Pedesseau, Claudine Katan, Jacky Even. On the entanglement of electrostriction and non-linear piezoelectricity in non-centrosymmetric materials. Applied Physics Letters, 2012, 100, pp.031903. 10.1063/1.3676666 . hal-00664196

\section{HAL Id: hal-00664196 https://hal.science/hal-00664196}

Submitted on 30 Jan 2012

HAL is a multi-disciplinary open access archive for the deposit and dissemination of scientific research documents, whether they are published or not. The documents may come from teaching and research institutions in France or abroad, or from public or private research centers.
L'archive ouverte pluridisciplinaire HAL, est destinée au dépôt et à la diffusion de documents scientifiques de niveau recherche, publiés ou non, émanant des établissements d'enseignement et de recherche français ou étrangers, des laboratoires publics ou privés. 


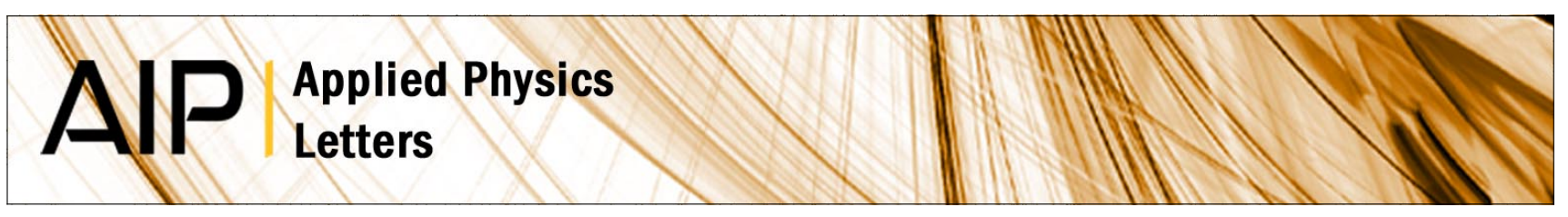

\section{On the entanglement of electrostriction and non-linear piezoelectricity in non-centrosymmetric materials}

L. Pedesseau, C. Katan, and J. Even

Citation: Appl. Phys. Lett. 100, 031903 (2012); doi: 10.1063/1.3676666

View online: http://dx.doi.org/10.1063/1.3676666

View Table of Contents: http://apl.aip.org/resource/1/APPLAB/v100/i3

Published by the American Institute of Physics.

\section{Related Articles}

Stress-controlled $\mathrm{Pb}(\mathrm{ZrO}$.52Ti0.48)O3 thick films by thermal expansion mismatch between substrate and $\mathrm{Pb}(\mathrm{ZrO} 0.52 \mathrm{Ti0} .48) \mathrm{O} 3$ film

J. Appl. Phys. 110, 124101 (2011)

Electric field controlled magnetization rotation in exchange biased antiferromagnetic/ferromagnetic/piezoelectric composites

Appl. Phys. Lett. 99, 232502 (2011)

Enhanced piezoelectric response of $\mathrm{BaTiO}-\mathrm{KNbO} 3$ composites

Appl. Phys. Lett. 99, 202902 (2011)

A coupled analysis of the piezoresponse force microscopy signals

Appl. Phys. Lett. 99, 171913 (2011)

Correlation between dielectric properties and chemical composition of the tourmaline single crystals

Appl. Phys. Lett. 99, 142906 (2011)

\section{Additional information on Appl. Phys. Lett.}

Journal Homepage: http://apl.aip.org/

Journal Information: http://apl.aip.org/about/about_the_journal

Top downloads: http://apl.aip.org/features/most_downloaded

Information for Authors: http://apl.aip.org/authors

\section{ADVERTISEMENT}

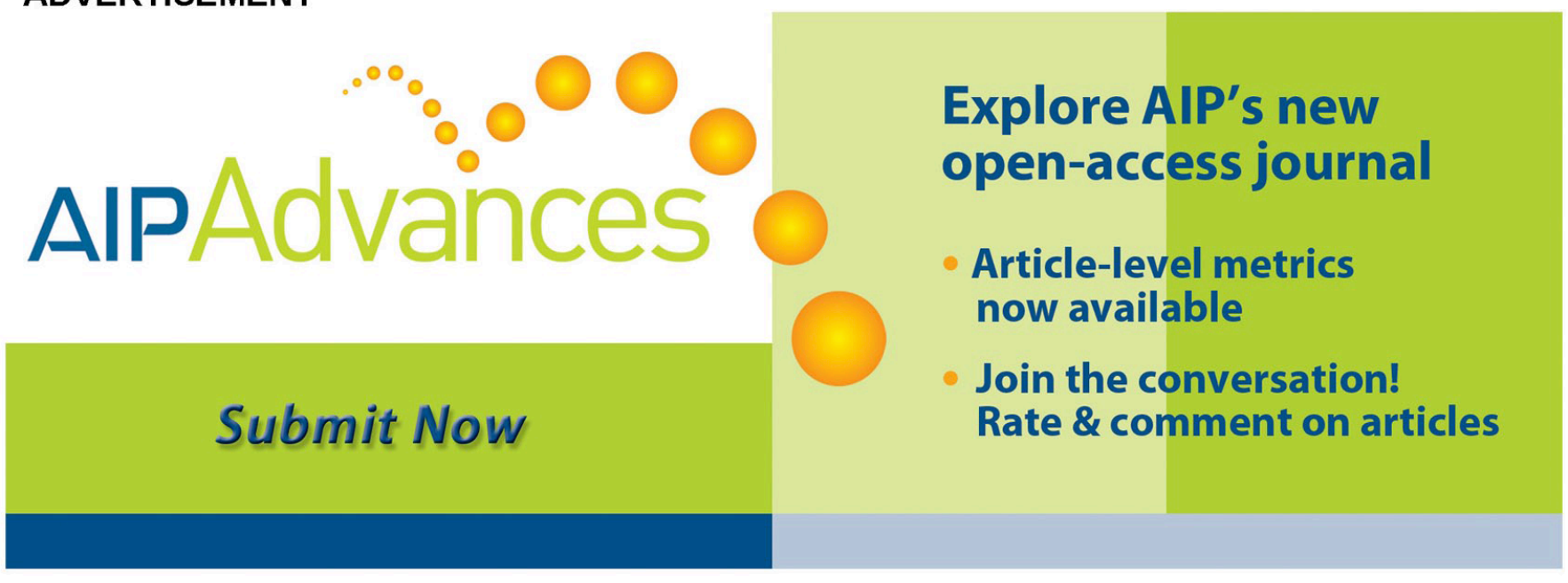




\title{
On the entanglement of electrostriction and non-linear piezoelectricity in non-centrosymmetric materials
}

\author{
L. Pedesseau, C. Katan, and J. Even ${ }^{\text {a) }}$ \\ Université Européenne de Bretagne, France and FOTON, UMR 6082, INSA, F-35708 Rennes, France
}

(Received 17 November 2011; accepted 22 December 2011; published online 17 January 2012)

\begin{abstract}
An extended and complete thermodynamical model of third-order electro-elastic coupling is proposed with symmetry analyses and density functional theory (DFT) calculations to evaluate consistently the various linear and non-linear coefficients. It is shown that in non-centrosymmetric materials, electrostrictive and non-linear piezoelectric phenomena are strongly coupled, except for materials crystallizing in a cubic lattice associated to the 432 point group. Thorough numerical results are given for $\mathrm{GaN}$ and $\mathrm{AlN}$ compounds in the Würtzite structure. Electrostriction dominates, but non-linear elasticity and non-linear piezoelectricity must be taken into account for strain evaluation whereas non-linear piezoelectricity yields a significant correction for electric field. (C) 2012 American Institute of Physics. [doi:10.1063/1.3676666]
\end{abstract}

Electrostrictive materials and generally materials which display large electromechanical interactions can be exploited in the areas of stress or displacement sensing and in actuating. ${ }^{1,2}$ It is also known that electrostrictive strains and large applied fields may cause breakdown of insulator materials used in small microelectronics devices. Non-linear elastic and piezoelectric effects in semiconductors have attracted attention in the last few years because highly strained materials are used intentionally to grow lattice mismatched nanostructures like quantum wells or quantum dots. ${ }^{3-7}$ The explanation of the observed first-order phase transition in ferroelectric materials like $\mathrm{BaTiO}_{3}$ or $\mathrm{SrTiO}_{3}$ requires the presence of suitable electrostrictive terms in the expression for the free energy of the material. ${ }^{8,9}$ Devonshire's theory relates the piezoelectric coefficients of the material in the polarized phase to the electrostrictive coefficients of the material in the unpolarized phase. In most experimental or theoretical works, ${ }^{10-14}$ nonlinearity in electrical, elastic, and electromechanical properties has been defined using formalisms related to Devonshire'theory. Yet, an extended and complete model of third-order electro-elastic coupling has been proposed in Ref. 14 using a systematic thermodynamical approach (Adam-Tichy-Kittinger model has been quoted ATK model in this paper).

Indeed, this letter aims to show that the ATK model can be combined systematically with symmetry analyses and DFT calculations to evaluate consistently the various linear and non-linear coefficients, especially in non-centrosymmetric materials. Symmetry properties of third-order elastic constants are well known ${ }^{15,16}$ but have been extensively studied for third-order coupled constants only more recently. ${ }^{17,18}$ The methods of density-functional perturbation theory (DPFT) may be used to calculate various physical responses. In fact, the efficient use of the " $2 n+1$ " theorem, ${ }^{20}$ using only byproducts of a first-order perturbation calculation, ${ }^{19-21}$ allows in principle to obtain the second and third-order derivatives of the total energy at the level of the ATK model, when the atomic-displacement variables are eliminated. Second-order derivatives of the total energy may be used with an existing

\footnotetext{
${ }^{\text {a) }}$ Author to whom correspondence should be addressed. Electronic mail: jacky.even@insa-rennes.fr.
}

DPFT implementation $^{22}$ to calculate various physical response properties of insulating crystals. Third-order derivatives are related to a number of physical properties described in this work, like the electrostrictive effects. However, most practical implementations of the DPFT are restricted to some quantities related to internal atomic displacements. In this paper, thirdorder coefficients are mostly determined from finite difference studies of materials polarisation or stress tensor under various electrical or strain conditions.

Here, we introduce thermodynamic potentials using standard definitions ${ }^{23,24}$ for the free enthalpy $\mathrm{G}=\mathrm{U}-\sigma_{\mathrm{i}} \eta_{\mathrm{i}}-\mathrm{TS}$, the transformed free enthalpy $G_{e}=U-\sigma_{i} \eta_{i}-T S-E_{l} D_{l}$, and free energy $F_{e}=U-T S-E_{l} D_{l}$. The $D_{l}, E_{l}$ vectors and the $\eta_{i}, \sigma_{i}$ strain-stress tensors (in Voigt notation) are associated, respectively, to the $l, m, n, u, v, o$ and $i, j, k, p, q, r$ indices varying between 1-3 and 1-6. Three second-orders are defined for each of the thermodynamic potentials

$$
\begin{gathered}
d \sigma_{i}=C_{i j}^{E} d \eta_{j}-e_{i l} d E_{l} \text { and } d D_{l}=e_{l i} d \eta_{i}+\varepsilon_{l m}^{\eta} d E_{m} \text { for } F_{e}, \\
d \eta_{i}=S_{i j}^{E} d \sigma_{j}+d_{i l} d E_{l} \text { and } d D_{l}=d_{l i} d \sigma_{i}+\varepsilon_{l m}^{\sigma} d E_{m} \text { for } G_{e}, \\
d \eta_{i}=S_{i j}^{D} d \sigma_{j}+g_{i l} d D_{l} \text { and } d E_{l}=-g_{l i} d \sigma_{i}+\beta_{l m}^{\sigma} d D_{m} \text { for } G .
\end{gathered}
$$

The second-order derivatives of the thermodynamic potentials are related to each others by exact relations ${ }^{23,24}$ like $\varepsilon_{l m}^{\sigma}-\varepsilon_{l m}^{\eta}=e_{l j} S_{j i}^{E} e_{i m}, e_{i l}=C_{i j}^{E} d_{j l}, S_{i j}^{E}-S_{i j}^{D}=g_{i l} d_{l j}$. Four third-order derivatives are defined for $F_{e}, G_{e}$, and $G$

$$
\begin{aligned}
d C_{i j}^{E} & =C_{i j k}^{E} d \eta_{k}-B_{i j l} d E_{l}, d e_{l i}=B_{l i j} d \eta_{j}+L_{\mathrm{lim}} d E_{m}, \text { and } d \varepsilon_{l m}^{\eta} \\
& =L_{l m i} d \eta_{i}+\varepsilon_{l m n}^{\eta} d E_{n}, \\
d S_{i j}^{E} & =S_{i j k}^{E} d \sigma_{k}+F_{i j l} d E_{l}, d d_{l i}=F_{l i j} d \sigma_{j}+M_{\mathrm{lim}} d E_{m}, \text { and } d \varepsilon_{l m}^{\sigma} \\
& =M_{l m i} d \sigma_{i}+\varepsilon_{l m n}^{\sigma} d E_{n}, \\
d S_{i j}^{D} & =S_{i j k}^{D} d \sigma_{k}+R_{i j l} d D_{l}, d g_{l i}=R_{l i j} d \sigma_{j}+Q_{l m i} d D_{m}, \text { and } d \beta_{l m}^{\sigma} \\
& =-Q_{l m i} d \sigma_{i}+\beta_{l m n}^{\sigma} d D_{n} .
\end{aligned}
$$

Most of these quantities are already used in various papers, but we will focus on the non-linear piezoelectric 
tensors $B_{l i j}$ (Refs. 3-7, 17, and 18) and $F_{l i j}, R_{l i j}$ (Refs. 17 and 18 ) and the electrostrictive tensors $L_{l m i},{ }^{17} M_{l m i}$, and $Q_{l m i} .{ }^{8-13}$ The third-order derivatives of the thermodynamic potentials are also related to each other by various exact relations (adapted from ATK model)

$$
F_{l i j}=S_{i k}^{E} B_{l k p} S_{p j}^{E}+e_{l k} S_{k i j}^{E}
$$

and

$$
\begin{gathered}
R_{l i j}=\beta_{l m}^{\sigma} F_{m i j}-\beta_{l m}^{\sigma} \beta_{n v}^{\sigma}\left(M_{m n i} d_{v j}+M_{m n j} d_{v i}\right)-\beta_{l m n}^{\sigma} d_{m i} d_{n j}, \\
Q_{l m i}=\beta_{l m n}^{\sigma} d_{n i}+\beta_{m n}^{\sigma} \beta_{l v}^{\sigma} M_{v n i} \text { and } \\
M_{l m i}=\left(B_{l k p} d_{m p}+B_{m k p} d_{l p}\right) S_{k i}^{E}+L_{l m j} S_{j i}^{E}+e_{l k} e_{m j} S_{k j i}^{E} .
\end{gathered}
$$

These relations show that the tensors can be strongly entangled. Coefficients defined for a specific thermodynamical potential cannot be mixed with others in the same theoretical model without caution. For example, in the case of non-centrosymmetric materials, an additional term related to the linear piezoelectricity and the non-linear susceptibility must be added to the commonly used relation $Q_{l m i}$ $=\beta_{m n}^{\sigma} \beta_{l v}^{\sigma} M_{v n i}{ }^{11}$ Experimental determination of piezoelectric and electrostrictive entangled components must also rely on careful definitions of experimental conditions which makes such measurements very involved. ${ }^{11}$ The direction of the applied field and the frequency behaviour are useful tools to separate the strains arising from piezoelectricity and electrostriction.

It is necessary to use symmetry properties of the materials in order to check whether or not the entanglement has to be taken into account. In order to get a first insight into the influence of lattice symmetry, we may compare materials which crystallise in a cubic lattice associated either to the $\mathrm{m} 3 \mathrm{~m}$ (e.g., diamond or undistorted perovskite lattices) and 432 point groups. In both cases, the linear piezoelectric tensors and nonlinear susceptibilities are vanishing. Only six independent non-linear elastic constants and compliances exist. ${ }^{14,15} Q_{l m i}$, $M_{l m i}$, and $L_{l m i}$ tensors related to electrostriction are simply related, like in isotropic materials: $Q_{l m i}=\beta_{m n}^{\sigma} \beta_{l v}^{\sigma} M_{v n i}$ and $M_{l m i}=L_{l m j} S_{j i}^{E}$, although the number of independent coefficients is larger. The only difference between the $\mathrm{m} 3 \mathrm{~m}$ and 432 point groups comes from the non-linear piezoelectricity phenomenon which appears only in the 432 case. Among the 32 crystal classes, 11 are centrosymmetric ( $\mathrm{m} 3 \mathrm{~m}$ case) and 21 are non-centrosymmetric, but of these, 432 is a special case. For point group 432, non-linear piezoelectricity and electrostriction are indeed disentangled, and only one independent component $B_{124}$ has to be determined: $F_{124}=\left(S_{11}^{E}-S_{12}^{E}\right)$ $B_{124} S_{44}^{E}=\varepsilon^{\sigma} R_{124}$. However, in order to experimentally or theoretically study non-linear piezoelectric phenomenon from the polarization, the crystal must be strained simultaneously in a non-hydrostatic and shear strain state, as seen from the expression of the electric polarization (within cartesian coordinates and using Voigt notation for strain) $P=B_{124}\left(\left(\eta_{2}-\eta_{3}\right) \eta_{4}\right.$, $\left.\left(\eta_{3}-\eta_{1}\right) \eta_{5},\left(\eta_{1}-\eta_{2}\right) \eta_{6}\right)$.

The case of the non-centrosymmetric $\overline{4} 3 m$ point group is more complex but corresponds to a large number of semiconductor materials of technological interest crystallizing in the zinc-blende lattice. ${ }^{3-5}$ Linear piezoelectric tensors and non-linear susceptibilities correspond only to one non-zero component. Non-linear piezoelectric tensor has three independent components: $B_{114}, B_{124}, B_{156}{ }^{3,4,17,18}$ The relations between $B_{l i j}, F_{l i j}$, and $R_{l i j}$ are more complex than for the 432 point group as illustrated by $F_{156}=S_{44}^{E} B_{156} S_{44}^{E}+e_{14} S_{456}^{E}$. Only one of the three independent electrostrictive components $\boldsymbol{Q}_{l m i}$ contains an additional contribution: $Q_{234}$ $=\beta_{123}^{\sigma} d_{14}+\beta^{\sigma} \beta^{\sigma} M_{234}$. The electrostrictive and non-linear piezoelectric tensors, respectively, $M_{l m i}$ and $B_{l i j}$, are no longer independent as illustrated by $M_{111}=d_{14}\left(2 B_{114} S_{11}^{E}\right.$ $\left.+4 B_{124} S_{12}^{E}\right)+L_{111} S_{11}^{E}+2 L_{112} S_{12}^{E}+e_{14} e_{14} S_{144}^{E}$.

Among the hexagonal piezoelectric crystal classes, the 622 class is the most simple (e.g., beta quartz crystallographic structure). Only one linear and three non-linear piezoelectric components have to be defined. ${ }^{17,18}$ In this case, for quantum nanostructures with axial symmetry geometries, it is possible to use a cylindrical representation $(r, \varphi, z)$ in linear elasticity. ${ }^{4,5,25}$ The components of the strain tensor depend only on four quantities $\varepsilon_{r r}(r, z), \varepsilon_{\varphi \varphi}(r, z), \varepsilon_{z z}(r, z)$, $\varepsilon_{r z}(r, z)$ and the piezoelectric polarization has only an

\begin{tabular}{|c|c|c|}
\hline & AlN & $\mathrm{GaN}$ \\
\hline $\mathrm{a}(\AA)$ & 3.060 & 3.219 \\
\hline c $(\AA)$ & 4.898 & 5.244 \\
\hline $\mathrm{c}_{11}(\mathrm{GPa})$ & 408 & 339 \\
\hline $\mathrm{c}_{12}(\mathrm{GPa})$ & 138 & 133 \\
\hline $\mathrm{c}_{13}(\mathrm{GPa})$ & 106 & 99 \\
\hline $\mathrm{c}_{33}(\mathrm{GPa})$ & 380 & 375 \\
\hline $\mathrm{c}_{111}(\mathrm{GPa})$ & -1525 & -1225 \\
\hline $\mathrm{c}_{112}(\mathrm{GPa})$ & -374 & -834 \\
\hline $\mathrm{c}_{113}(\mathrm{GPa})$ & -66 & -283 \\
\hline $\mathrm{c}_{123}(\mathrm{GPa})$ & -688 & -631 \\
\hline $\mathrm{c}_{133}(\mathrm{GPa})$ & -1117 & -967 \\
\hline $\mathrm{c}_{222}(\mathrm{GPa})$ & -271 & -974 \\
\hline $\mathrm{c}_{333}(\mathrm{GPa})$ & -56 & -1126 \\
\hline $\mathrm{L}_{11}$ & 11.9 & 23.3 \\
\hline $\mathrm{L}_{12}$ & 8.9 & 9.8 \\
\hline $\mathrm{L}_{13}$ & 7.3 & 11.2 \\
\hline $\mathrm{L}_{31}$ & 37.4 & 27.6 \\
\hline $\mathrm{L}_{33}$ & -73.6 & -84.4 \\
\hline $\mathrm{L}_{44}$ & 3.6 & 9.9 \\
\hline$\varepsilon_{11}$ & 5.3 & 7.0 \\
\hline$\varepsilon_{33}$ & 5.5 & 7.0 \\
\hline$\varepsilon_{113}\left(10^{-12} \mathrm{~m} / \mathrm{V}\right)$ & 212 & 285 \\
\hline$\varepsilon_{333}\left(10^{-12} \mathrm{~m} / \mathrm{V}\right)$ & $\sim 0$ & 985 \\
\hline$\varepsilon_{3333}\left(10^{-18} \mathrm{~m} / \mathrm{V}\right)$ & -17.6 & -0.9 \\
\hline $\mathrm{e}_{31}\left(\mathrm{C} / \mathrm{m}^{2}\right)$ & -0.67 & -0.41 \\
\hline $\mathrm{e}_{33}\left(\mathrm{C} / \mathrm{m}^{2}\right)$ & 1.67 & 0.76 \\
\hline $\mathrm{e}_{15}\left(\mathrm{C} / \mathrm{m}^{2}\right)$ & -0.35 & -0.29 \\
\hline $\mathrm{B}_{311}\left(\mathrm{C} / \mathrm{m}^{2}\right)$ & 3.77 & 6.26 \\
\hline $\mathrm{B}_{312}\left(\mathrm{C} / \mathrm{m}^{2}\right]$ & 4.12 & 2.37 \\
\hline $\mathrm{B}_{313}\left(\mathrm{C} / \mathrm{m}^{2}\right)$ & -8.64 & -1.47 \\
\hline $\mathrm{B}_{333}\left(\mathrm{C} / \mathrm{m}^{2}\right)$ & -25.60 & -23.43 \\
\hline $\mathrm{B}_{115}\left(\mathrm{C} / \mathrm{m}^{2}\right)$ & 8.69 & 6.48 \\
\hline $\mathrm{B}_{125}\left(\mathrm{C} / \mathrm{m}^{2}\right)$ & 5.19 & 5.09 \\
\hline $\mathrm{B}_{135}\left(\mathrm{C} / \mathrm{m}^{2}\right)$ & 3.20 & 7.02 \\
\hline $\mathrm{B}_{344}\left(\mathrm{C} / \mathrm{m}^{2}\right)$ & 2.88 & 1.41 \\
\hline $\mathrm{P}_{\mathrm{sp}}\left(\mathrm{C} / \mathrm{m}^{2}\right)$ & -0.075 & -0.014 \\
\hline
\end{tabular}

TABLE I. Electric and strain-related materials for AlN and GaN using DFT-LDA calculations via the ABINIT code. ${ }^{22} \varepsilon_{\mathrm{ij}}$ and $\mathrm{L}_{\mathrm{ij}}$ are the relative dielectric and electrostrictive tensors, respectively. 


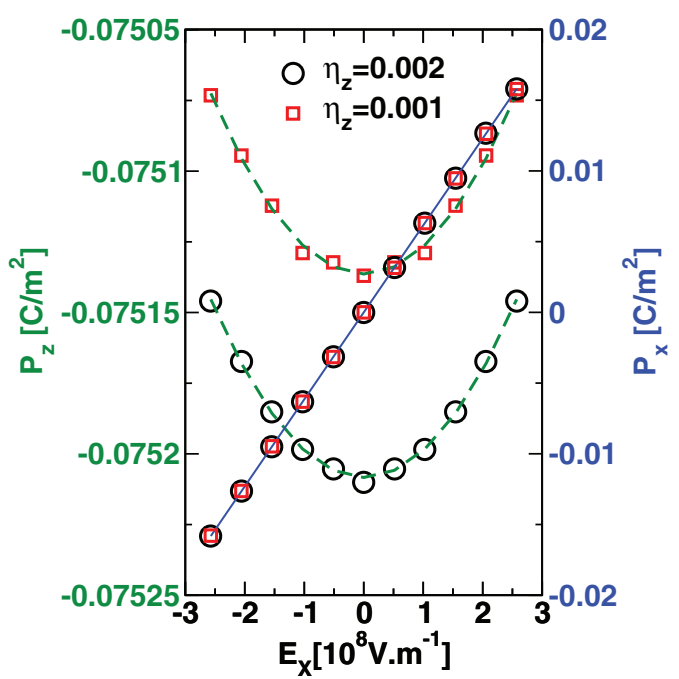

FIG. 1. (Color online) Variations of $P_{x}$ and $\boldsymbol{P}_{z}$ as a function of $E_{x}$ for AlN and various strain states along $o z$. The zero field and zero strain values of $\boldsymbol{P}_{z}$ are related to the spontaneous polarization, while the quadratic variation of $\boldsymbol{P}_{z}$ is related to the non-linear dielectric susceptibility.

angular component in cylindrical coordinates: $P_{\theta}=-2 \varepsilon_{r z}\left(e_{14}+B_{124} \varepsilon_{r r}+B_{124} \varepsilon_{\theta \theta}+B_{134} \varepsilon_{z z}\right)$. It is then straightforward to show that the internal electric field vanishes. For the electrostrictive tensor, $Q_{234}=\beta_{123}^{\sigma} d_{14}$ $+\beta^{\sigma} \beta^{\sigma} M_{234}$.

Ten of the non-centrosymmetric crystal classes represent the polar crystal classes, which show a spontaneous polarization. For all this crystal classes, the entanglement of non-linear piezoelectricity and electrostriction is very strong. The hexagonal $6 \mathrm{~mm}$ polar crystal class corresponds to a number of important materials in the wurtzite structure. ${ }^{6,7,12,26,27}$ We applied various electrical or strain conditions for the DFT determination of the coefficients in the case of the GaN and AIN crystals (Table I). Briefly, DFT simulations were performed through the $a b$ initio open source ABINIT computer package ${ }^{22}$ within the local density approximation (LDA). ${ }^{28}$ Plane wave basis sets were used with a kinetic energy cutoff of $950 \mathrm{eV}$ after convergence studies. The sets of k-points were generated following the procedure of Pack and Monkhorst ${ }^{28-30}$ namely $10 \times 10 \times 10$. The pseudo potentials were generated for $\mathrm{Ga}\left[3 \mathrm{~d}^{10} 4 \mathrm{~s}^{2} 4 \mathrm{p}^{1}\right]$ atom via the OPIUM code ${ }^{31,32}$ and for $\mathrm{Al}\left[3 \mathrm{~s}^{2} 3 \mathrm{p}^{1}\right]$ and $\mathrm{N}$ $\left[2 \mathrm{~s}^{2} 2 \mathrm{p}^{3}\right]$ atoms via the FHI98PP code. ${ }^{33}$ In Figure 1, the variations of $P_{x}$ and $\boldsymbol{P}_{z}$ are reported for AlN and different strain states, as a function of $E_{x}$. The zero field and zero strain magnitude of $\boldsymbol{P}_{z}$ is related to the spontaneous polarization while the quadratic variation of $\boldsymbol{P}_{z}$ is related to the nonlinear dielectric susceptibility. For GaN, the higher order electric (Kerr) effect dominates (Table I). The values of the cell parameters or linear coefficients are similar to those previously reported in the literature. If we consider a pure biaxial strain state perpendicular to the usual growth direction for nitride heterostructures $(\mathrm{oz})$, the polarisation has only one component $\quad P_{z}=P_{s p}+e_{33} \varepsilon_{\perp}+2 e_{31} \varepsilon_{/ /}+\left(B_{311}+B_{312}\right) \varepsilon_{/ /}^{2}$ $+\frac{B_{333}}{2} \varepsilon_{\perp}^{2}+2 B_{313} \varepsilon_{/ /} \varepsilon_{\perp}$. In the corresponding relation given in Ref. 7, indices are interchanged but, more importantly, incorrect numerical prefactors and one of the eight tensor components namely $\boldsymbol{B}_{312}$ are lacking. Given these corrections, both DFT studies give similar numerical values, except for the

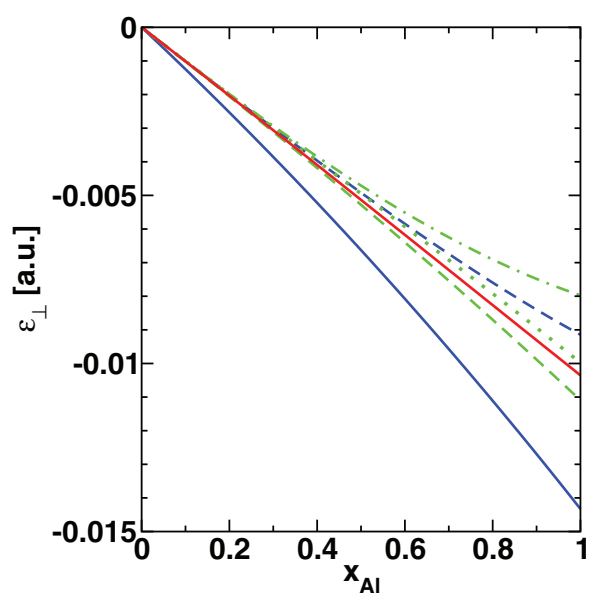

FIG. 2. (Color online) Variation of $\varepsilon_{\perp}$ as a function of $\mathrm{Al}$ mole fraction for various models. The results of the uncoupled and coupled linear models are represented by straight and dashed blue lines (the first (bottom) and the fifth curves), the coupling etc. The straight red line (third curve) includes all the non-linear contributions. The electrostrictive, the non-linear elastic and the non-linear piezoelectric ones are represented by dashed (second curve), dashed/dotted (sixth curve), and dotted green lines (fourth curve).

$B_{313}$ that remains in both cases much more important for AlN than GaN. The electromechanical coupling can be studied in $\mathrm{AlGaN} / \mathrm{GaN}$ heterojunctions ${ }^{27}$ including all the nonlinear effects. Figure 2 shows the variation of $\varepsilon_{\perp}$ as a function of Al mole fraction for various models. The coupling strongly reduces $\varepsilon_{\perp}$ in linear models. It is, however, overestimated as shown by the straight red line including all the nonlinear contributions. Among these, the electrostrictive, the non-linear elastic and the non-linear piezoelectric ones are the most important (in decreasing order). The non-linear elastic contribution is opposite to the other ones. Variation of the electric field $E_{z}$, as a function of $\mathrm{Al}$ mole fraction, is reported in Figure 3 for various models. The coupling strongly enhances $E_{z}$ in linear models. Once more, when including all the non-linear contributions, the electrostrictive

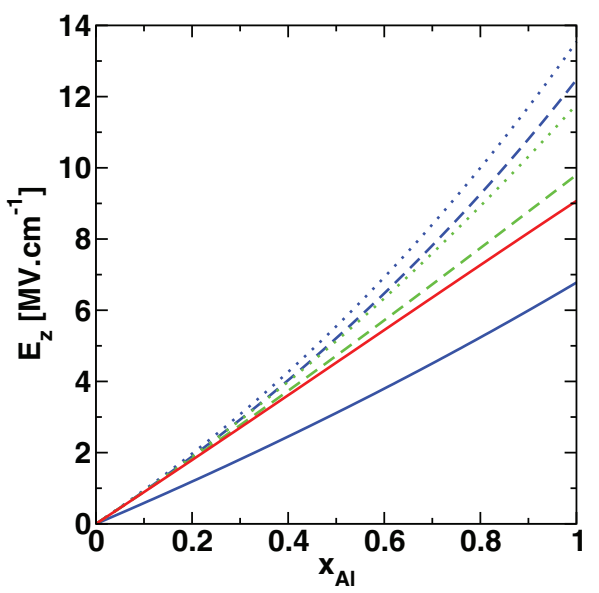

FIG. 3. (Color online) Variation of the electric field $E_{z}$ as a function of $\mathrm{Al}$ mole fraction for various models. The results of the uncoupled and coupled linear models are represented by straight (first (bottom) curve) and dashed (fifth curve) blue lines, the coupling strongly enhancing $E_{z}$. The linear semicoupled "standard" model, ${ }^{27}$ is represented by a dotted blue line (sixth curve). The straight red line (second curve) includes all the non-linear contributions. The electrostrictive and the non-linear piezoelectric ones are represented by dashed (third curve) and dotted (fourth curve) green lines. 
contribution dominates and reduces the effect of coupling (Figure 3). Using relation $M_{l m i}=\left(B_{l k p} d_{m p}+B_{m k p} d_{l p}\right) S_{k i}^{E}$ $+L_{l m j} S_{j i}^{E}+e_{l k} e_{m j} S_{k j i}^{E}$, it is shown that whatever the Al mole fraction, the most important contribution to $M_{33}$ is due to $L_{l m i}$ but non-linear piezoelectric effect can no longer be ignored. $M_{33}$ calculated for GaN $\left(2.8 \times 10^{-21} \mathrm{~m}^{2} \mathrm{~V}^{-2}\right)$ is rather large ${ }^{11}$ but much smaller than the record experimental value of $1.8 \times 10^{-18} \mathrm{~m}^{2} \mathrm{~V}^{-2}$ reported in Ref. 12. This experimental result has, however, not yet been confirmed, neither for $\mathrm{GaN}$ nor for any other semiconductor compounds. We may underline that in this field, incomplete formula for the $M_{l m i}$ tensor have been used up to now. ${ }^{6,34,35}$

An extended and self-contained thermodynamical model of third-order electro-elastic coupling is used with symmetry analyses and DFT calculations to evaluate properly the various linear and non-linear coefficients. It is shown that in noncentrosymmetric materials, electrostrictive and non-linear piezoelectric phenomena are strongly coupled, except for materials crystallizing in a cubic lattice associated to point group 432. The whole simulations have been explored for GaN and AlN compounds in the Würtzite structure. For these materials, both phenomena must be taken into account simultaneously at the same level of theory or experiment. Electrostriction dominates, but non-linear elasticity and non-linear piezoelectricity must be taken into account for strain evaluation, whereas nonlinear piezoelectricity yields a significant correction for electric field. Coupled linear models overestimate the corrections with respect to uncoupled linear ones and we recommend the use of full coupled non-linear models.

${ }^{1}$ R. E. Pelrine, R. D. Kornbluh, and J. P. Joseph, Sens. Actuators, A 64, 77 (1998).

${ }^{2}$ A. Wingert, M. D. Lichter, and S. Dubowsky, IEEE/ASME Trans. Mechatron. 11, 448 (2006).

${ }^{3}$ G. Bester, X. Wu, D. Vanderbilt, and A. Zunger, Phys. Rev. Lett. 96, 187602 (2006).
${ }^{4}$ J. Even, F. Doré, C. Cornet, L. Pédesseau, A. Schliwa, and D. Bimberg, Appl. Phys. Lett. 91, 122112 (2007).

${ }^{5}$ J. Even, F. Doré, C. Cornet, and L. Pedesseau, Phys. Rev. B 77, 085305 (2008).

${ }^{6}$ L. C. Lew Yan Voon and M. Willatzen, J. Appl. Phys. 109, 031101 (2011).

${ }^{7}$ J. Pal, G. Tse, V. Haxha, and M. A. Migliorato, Phys. Rev. B 84, 085211 (2011).

${ }^{8}$ A. F. Devonshire, Adv. Phys. 3, 94 (1954).

${ }^{9}$ G. Rupprecht and D. Winter, Phys. Rev. 155, 1019 (1967).

${ }^{10}$ Z. Y. Meng and L. E. Cross, J. Appl. Phys. 57, 491 (1985).

${ }^{11}$ R. E. Newnham, V. Sundar, R. Yimnirun, J. Su, and Q. M. Zhang, J. Phys. Chem. B 101, 10141 (1997).

${ }^{12}$ I. L. Guy, S. Muensit, and E. M. Goldys, Appl. Phys. Lett. 75, 3641 (1999).

${ }^{13}$ Y. Cho and K. Yamanouchi, J. Appl. Phys. 61, 875 (1986).

${ }^{14}$ W. Adam, J. Tichy, and E. Kittinger, J. Appl. Phys. 64, 2556 (1988).

${ }^{15}$ F. G. Fumi, Phys Rev. 83, 1274 (1951).

${ }^{16}$ K. Brugger, J. Appl. Phys. 36, 759 (1965).

${ }^{17}$ D. Gerlich and M. A. Breazeale, J. Appl. Phys. 68, 5119 (1990).

${ }^{18}$ H. Grimmer, Acta Cryst. A 63, 441 (2007).

${ }^{19}$ S. Baroni, P. Gianozzi, and A. Testa, Phys. Rev. Lett. 59, 2662 (1987).

${ }^{20}$ X. Gonze and J. P. Vigneron, Phys. Rev. B 39, 13120 (1989).

${ }^{21}$ D. R. Hamann, X. Wu, K. M. Rabe, and D. Vanderbilt, Phys. Rev. B 71, 035117 (2005).

${ }^{22}$ X. Gonze, B. Amadon, P.-M. Anglade, J.-M. Beuken, F. Bottin, P. Boulanger, F. Bruneval, D. Caliste, R. Caracas, M. Cote et al., Comput. Phys. Commun. 180, 2582 (2009).

${ }^{23}$ J. F. Nye, Physical Properties of Crystals: Their Representation by Tensors and Matrices (Oxford University Press, New York, 1985).

${ }^{24} \mathrm{E}$ Dieulesaint and D Royer, Ondes élastiques dans les solides - propagation libre et guidée (Masson, Paris Milan Barcelone, 1996).

${ }^{25}$ J. Even, Appl. Phys. Lett. 94, 102105 (2009).

${ }^{26}$ I. Vurgaftman and J. R. Meyer, J. Appl. Phys. 94, 3675 (2003).

${ }^{27}$ B. Jogai, J. D. Albrecht, and E. Pan, J. Appl. Phys. 94, 3984 (2003).

${ }^{28}$ J. P. Perdew and Y. Wang, Phys. Rev. B 45, 13244 (1992).

${ }^{29}$ H. J. Monkhorst and J. D. Pack, Phys. Rev. B 13, 5188 (1976).

${ }^{30}$ J. D. Pack and H. J. Monkhorst, Phys. Rev. B 16, 1748 (1977).

${ }^{31}$ G. G. P. Licence, Opium code version 3.6 (October 2010), http:// opium.sourceforge.net.

${ }^{32}$ I. Grinberg, N. Ramer, and A. Rappe, Phys. Rev. B 62, 2311 (2000).

${ }^{33}$ M. Fuchs and M. Scheffler, Comput. Phys. Commun. 119, 67 (1999).

${ }^{34}$ M. Bahrami-Samani, S. R. Patil, and R. Melnik, J. Phys.: Condens. Matter 22, 495301 (2010).

${ }^{35}$ I. Kornev, M. Willatzen, B. Lassen, and L. C. Lew Yan Voon, AIP Conf. Proc. 1199, 71 (2010). 